

\title{
Desde la influencia del darwinismo social hasta el imperio de los derechos humanos. Inmigración en Chile entre 1907 y 2018*
}

\author{
José Antonio González-Pizarro**
}

\section{Resumen}

Se analizan las políticas migratorias implementadas por el Estado de Chile entre dos hitos de la explosión migratoria cuyos censos nacionales de población, 1907 y 2018, marcaron los mayores porcentajes de extranjeros en el país. Para ello se estudia la normativa migratoria chilena, con sus correspondientes contextos, el de 1907, con la influencia del denominado darwinismo social que influyó en el racismo, la xenofobia de la sociedady, el de 2018, con la incidencia de los derechos humanos en la legislación nacional y con la persistencia de elementos percibidos en 1907. Esta convergencia de ideas en la sociedad y acciones estatales, se aplica a segmentos inmigratorios extracontinentales en 1907 y a contingentes inmigratorios continentales en 2018.

Palabras claves: inmigración; leyes; Chile; darwinismo; derechos humanos.

\section{From the influence of social darwinism to the reign of human rights. Immigration in chile between 1907 and 2018}

\section{Summary}

We analyze the migration policies implemented by the State of Chile between two milestones in the migratory explosion, 1907 and 2018, at which the national population censuses recorded the highest percentages of foreigners in the country. To do this, we study Chilean immigration regulations, with their corresponding contexts: the context in 1907, with the influence of so-called social Darwinism that influenced racism, society's xenophobia, and in 2018, with the incidence of human rights in national legislation and with the persistence of elements perceived in 1907. This convergence of ideas in society and State actions applies to extra-continental immigration segments in 1907 and continental immigration groups in 2018.

Keywords: immigration; laws; Chile; darwinism; human rights.

\section{Da a influência do darwinismo social até o império dos direitos humanos. Imigração no chile entre 1907 e 2018}

\section{Resumo}

Analisam-se as políticas migratórias implementadas pelo Estado Chileno entre dois momentos importantes da explosão migratória, como censos nacionais de população, 1907 e 2018, que registraram as maiores percentagens de expatriados na nação. Consequentemente, estuda-se a normatividade da migração no Chile, com a sua contextualização mais atinente, a de 1907 , com a influência do denominado darwinismo social que afetou o racismo, a xeno fobia da sociedade, e no 2018, com a incidência dos direitos humanos na Legislação nacional e com a prevalência dos elementos detectados em 1907. Essa convergência de ideias na sociedade e nas ações do Estaduais se aplica aos segmentos da imigração extracontinental em 1907 e aos grupos de imigração continental em 2018. Palavras-chave: imigração; leis; Chile; darwinismo; direitos humanos.

Artículo de investigación. El trabajo es parte del proyecto Fondecyt 1180319: "Estudio comparado sobre la migración asiática y la del Medio Oriente en Antofagasta y Valparaíso entre 1880 a 1930", año 2019 (término año 2020), y del proyecto IMI-UCN, Vicerrectoría de Investigación y Desarrollo Tecnológico, de la Universidad Católica del Norte, Antofagasta, Chile, (término año 2019).

* Investigador José Antonio González Pizarro, Escuela de Derecho-Antofagasta, Facultad de Ciencias Jurídicas de la Universidad Católica del Norte, Chile. Doctor en Historia por la Universidad de Navarra. Director del Centro de Estudios Histórico-Jurídicos de la Facultad de Ciencias Jurídicas de la Universidad Católica del Norte, Chile. Líneas de Investigación Migración- Estado-Sociedad- Derecho en el Norte de Chile. Correo electrónico: jagonzal@ucn.cl. ORCID: http://orcid.org/0000-0002-4030-0353

Cómo citar este artículo: González, J. A. (2020). Desde la influencia del darwinismo social hasta el imperio de los derechos humanos. Inmigración en Chile entre 1907 y 2018. Estudios de Derecho, 77 (169), 323-348

Doi: 10.17533/udea esde.v77n169a13

Fecha de recepción: 22/09/2019 Fecha de aprobación: 13/11/2019 


\section{Desde la influencia del darwinismo social hasta el imperio de los derechos humanos. Inmigración en Chile entre 1907 y 2018}

\section{Introducción}

En el devenir de Chile en materias migratorias durante los siglos XX y XXI, puede indicarse que el país vivió sujeto a las ideologías imperantes, avances en materias de derechos en pos de una sociedad más democrática y a las sensibilidades que la ciudadanía manifestó mediante variados escritos, desde tesinas, artículos de prensa hasta ensayos. En tal sentido, se debe puntualizar que lo aseverado nunca fue neutro en sus propósitos. Y esto tiene que ser apreciado en sus contextos históricos, donde ideas puntuales y sus presupuestos pudieron discurrir libremente alimentando prejuicios contra segmentos humanos o bien estas ideas fueron constreñidas por bienes jurídicos que se estimaron superiores, bajo otras circunstancias. En cada uno de estos marcos, las normativas nacionales, los instrumentos jurídicos internacionales y el moldeamiento de la sociedad respondieron a sus épocas y a determinados referentes para fijar cuáles flujos inmigratorios iban a ser tipificados como aceptables o indeseables. Esto nos lleva a ponderar de qué modo ideas, prejuicios y actitudes de antaño pudieron ser constatados en años recientes en el imaginario social nacional en específicos sectores sociales o en determinados lugares geográficos. De igual modo, interrogarse de qué manera han cristalizado los valores del canon de los derechos humanos en la legislación nacional y las formas con que han abordado los medios de comunicación social el fenómeno de la inmigración masiva.

Nuestra finalidad comparativa apunta a establecer la evolución en materias inmigratorias en los niveles del Estado y sus agencias, la legislación nacional y la incidencia en ella de las convenciones y tratados en materias de migración y derechos humanos y, por último, las prácticas que realiza el Estado y la opinión pública en el tratamiento de la inmigración.

El censo de población de 1907 señaló un ingreso inmigratorio (el más alto en el siglo XX) desde países vecinos, europeos y procedentes de Asia y del Medio 
Oriente que se acrecentó en el censo de 1920. En el censo de población de 2017 surgió el primer indicio que el porcentaje de extranjeros en el país había excedido el 4,1\% del total establecido en 1907, superado con creces en la actualización demográfica del año 2018.

Dos realidades sobre los habitantes que nos muestran ideas antitéticas sobre las "razas", la inmigración, las trabas para su ingreso hasta revelar acciones contradictorias ante los flujos inmigratorios por medio de leyes de distinta naturaleza para, finalmente, acatar en los primeros quinquenios del siglo actual, los diversos instrumentos internacionales que han orientado al Estado y las conductas sociales en asuntos inmigratorios.

Nuestra hipótesis es que entre fines del siglo XIX y primeras décadas del siglo XX confluyeron las ideas darwinistas y su aplicación al mundo social con la visión estatal chilena en pro de una política inmigratoria selectiva, a favor del europeo, que posibilitaron sentar una orientación gubernamental hacia la finalidad de acoger una inmigración que sirviera de ocupación/colonización de su prolongado territorio y pudiese contribuir al mejoramiento de las cualidades de su población actual. Empero, estas ideas y prácticas moldearon un imaginario social nacional de superioridad de corte esencialista que ha chocado con el canon de los derechos humanos suscrito por el Estado en el siglo XXI.

\section{Metodología}

El estudio combina la metodología histórica, con el análisis de los datos estadísticos demográficos en la evolución de Chile. Esto con relación a las ideologías imperantes, posturas del Estado y la opinión pública respecto al proceso de inmigración. Y la técnica jurídica en cuanto al análisis dogmático de la legislación internacional y nacional en materias del fenómeno migratorio. En esta perspectiva, el trabajo en cuestión entrecruza los datos empíricos demográficos con el análisis de la opinión pública recogida en la prensa, el abordamiento de iniciativas legales con los juicios emanados de los despachos diplomáticos.

Para tal finalidad, nos hemos basado en los cuerpos normativos, los censos nacionales de población, la documentación diplomática y regional depositada en el Archivo Nacional (Fondos de la Intendencia de Antofagasta y del Ministerio del Interior) y en el Archivo Histórico del Ministerio de Relaciones Exteriores de Chile.

\section{La situación migratoria de Chile en las primeras décadas del siglo XX}

Chile ha sido a lo largo de su historia un país expulsor de población, hasta el cambio en la segunda década del siglo XXI. Durante los siglos XIX y XX ejecutó una inmi- 
gración selectiva. Esto con la necesidad de poblar las tierras extremas del sur y el centro del país. Incorporados a Chile los territorios de Tarapacá y de Antofagasta, a consecuencia de la Guerra del Pacífico (1879-1884), se abrió un gran mercado laboral en las ciudades de Iquique y Antofagasta, derivado del monopolio mundial de la producción del nitrato de sodio-salitre, con sus respectivos hinterlands donde estaban las instalaciones industriales y campamentos respectivos. Esto significó que entre 1885 y 1925 hubo una versión acotada de la teoría del push and pull, pues atrajo población desde los países vecinos: Bolivia, Perú y Argentina. Y, gracias, a la globalización del liberalismo entre 1870 y 1920, donde la conectividad marítima y fuertes inversiones en la industria salitrera, posibilitó el arribo de importantes segmentos europeos al norte chileno.

Si se observan los censos de 1885 a 1930 tenemos una población nacional que aumenta muy poco entre 1885 a 1895 y de modo significativo entre 1895 a 1907. Se mantuvo estable en el lapso de 1907 a 1920 y continuó con menor intensidad entre 1920 y 1930 , como se aprecia en la tabla 1.

Tabla 1. Crecimiento de la población según censos nacionales

\begin{tabular}{llllll}
\hline Censo año & 1885 & 1895 & 1907 & 1920 & 1930 \\
\hline Población & 2.507 .380 & 2.695 .911 & 3.231 .496 & 3.731 .573 & 4.287 .445 \\
\hline
\end{tabular}

Fuente: Dirección General de Estadística, 1931, p. 40.

La llegada del contingente europeo, en general, a las principales ciudades chilenas, ha sido ponderada por su aporte al incremento de la capacidad empresarial nacional, al fortalecimiento de la clase media y al espíritu de trabajo y orden (Cano y Soffia, 2009).

Si apreciamos al contingente europeo más caracterizado y al latinoamericano más preponderante, encontramos en los censos en estudio los datos que refieren de su evolución, que se muestran en la Tabla 2.

No obstante, la inmigración europea se distribuyó entre las ciudades principales de Chile: Santiago, Valparaíso y Concepción; aunque hubo un número importante de ingleses en Iquique y Antofagasta; los latinoamericanos se concentraron en su mayoría en las provincias de Tarapacá y Antofagasta.

La presencia asiática se dispersó en las ciudades del norte de Chile, Iquique y Antofagasta. La china, en la antigua provincia peruana de Tarapacá, mezcló la originaria del tráfico de los culíes con otra reciente. Los súbditos procedentes desde Japón nunca fueron significativos en términos cuantitativos.

Después de la Primera Guerra Mundial se hizo notar otro segmento migratorio: los procedentes desde el Medio Oriente, súbditos del ex Imperio otomano. 
Desde la influencia del darwinismo social hasta el imperio...

Tabla 2. Población de Extranjeros según los censos nacionales de Chile

\begin{tabular}{llllll}
\hline Censo Año & 1885 & 1895 & 1907 & 1920 & 1930 \\
\hline Nacionalidad & 6.808 & 7.560 & 10.724 & 8.950 & 10.861 \\
$\begin{array}{l}\text { Alemania } \\
\text { Nacionalidad }\end{array}$ & 5.310 & 6.838 & 9.845 & 7.220 & 5.292 \\
$\begin{array}{l}\text { Inglaterra } \\
\text { Nacionalidad }\end{array}$ & 4.114 & 7.797 & 13.023 & 12.358 & 11.070 \\
$\begin{array}{l}\text { Italia } \\
\text { Nacionalidad }\end{array}$ & 2.508 & 8.494 & 18.755 & 25.962 & 23.439 \\
$\begin{array}{l}\text { España } \\
\text { Nacionalidad }\end{array}$ & 9.835 & 7.507 & 6.956 & 7.362 & 7.048 \\
Argentina & & & & & \\
Nacionalidad & 13.146 & 8.669 & 21.968 & 15.552 & 10.366 \\
Bolivia & & & & & \\
Nacionalidad & 34.901 & 15.999 & 27.140 & 12.991 & 6.223 \\
Perú & & & & & \\
\hline
\end{tabular}

Fuente: Dirección General de Estadística, 1933, vol. II, p. X.

Para sopesar la cuantía de los nacionales de China, Japón y del Medio Oriente, reparemos en el registro de la Tabla 3.

Tabla 3. Ciudadanos asiáticos y del Medio Oriente en Chile según censos nacionales

\begin{tabular}{llllll}
\hline Año Censo & 1885 & 1895 & 1907 & 1920 & 1930 \\
\hline Nacionales & 1.164 & 999 & 1.920 & 1.954 & 1.605 \\
$\begin{array}{l}\text { China } \\
\text { Nacionales }\end{array}$ & 51 & 20 & 209 & 557 & 670 \\
Japón & & & & & \\
Nacionales & 29 Turcos & 76 Turcos & 1.729 Turcos & 1.282 Turcos & 526 Turcos \\
Árabes & & & & 1.204 Sirios & 1.345 Sirios \\
& & & & 1.164 Palestinos & 3.156 Palestinos \\
\hline
\end{tabular}

Fuente: Dirección General de Estadística, 1933, vol. II, p. X. 
Empero, la realidad nortina exhibió para el año 1907 una interesante concentración de la denominada inmigración no deseable, pues en Tarapacá había 1.335 chinos, 98 japoneses y 90 turcos y en Antofagasta 287 chinos, 55 japoneses y 279 turcos (Comisión Central del Censo, 1907).

Para tener un panorama más amplio de los porcentajes de extranjeros a nivel nacional y entre las principales provincias del país, puede inferirse de los datos reunidos en la Tabla 4, la gravitación porcentual en la zona norte y en el sur magallánico.

Tabla 4. Extranjeros según censos nacionales y su proporción con la población, por provincia

\begin{tabular}{lllllllll}
\hline Provincias & 1885 & $\%$ & 1895 & $\%$ & 1907 & $\%$ & 1920 & $\%$ \\
\hline Tarapacá & 23.284 & 51.6 & 25.544 & 28.5 & 43.774 & 39.7 & 15.422 & 15.3 \\
Antofagasta & 6.519 & 5.1 & 6.210 & 14.0 & 17.800 & 15.7 & 15.722 & 9.1 \\
Valparaíso & 8.623 & 4.2 & 11.299 & 5.1 & 15.068 & 5.6 & 15.445 & 4.8 \\
Magallanes & 781 & 37.5 & 1.858 & 35.9 & 6.499 & 37.5 & 6.246 & 21.5 \\
Total Nacional & 87.077 & 3.4 & 79.056 & 2.9 & 134.524 & 4.1 & 120.436 & 3.2 \\
\hline
\end{tabular}

Fuente: Dirección General de Estadística, 1925, p. 277.

Estos antecedentes aportaron la base empírica para dar fundamento a la política estatal y a diversas expresiones discriminatorias cuando no racistas habidas en el norte de Chile.

\section{Ideologías de discriminación. Racismo y xenofobia contra la inmigración china y turca}

Apuntaba Hanna Arendt que la ideología era una "la lógica de una idea" (Arendt, 2004, p. 569) y en el curso del siglo XIX se estructuró una que afectó a las sociedades nacionales y moldeó las actitudes estatales frente al extranjero. Nos referimos a la convergencia de las ideas científicas de Charles Darwin, con otras derivadas de sus presupuestos fomentadas por Francis Galton, las aplicadas en el campo social por Herbert Spencer y otras que, sin rigor científico, aprovecharon las de Darwin para hacer planteamientos que prendieron en determinados círculos políticos, como fueron las sostenidas por Joseph Arthur de Gobineau y Houston S. Chamberlain. Gobineau, escribió Essai sur l'inegalité des races humaines en 1853 y, a su vez, Chamberlain, redactó su Die Grundlagen des neunzehnten Jarhunderts en 1890, o en su versión española Los Fundamentos del siglo XIX. Si el primero justificó la división de la humanidad entre razas superiores e inferiores, el segundo circunscribió la superioridad racial a lo germánico-nórdico. Esta combinación de 
ideas ayudó a alimentar manifestaciones racistas, segregacionistas y xenófobas en diversos círculos políticos y de la opinión pública, que dieron lugar a concreciones de políticas que fomentaron la eugenesia, la selectividad de la inmigración, la discriminación y prohibición sobre determinados segmentos inmigratorios. Fueron ideas que surgieron en Europa y tuvieron sus divulgadores e incluso fueron caldos de cultivos para ideologías totalitarias (Gurwitsch, 2010; La Placa, 2017; Weikart, 2013).

Nos interesa remarcar el cúmulo de premisas que dieron lugar a las reflexiones de los autores citados (y de otros). Y también, de qué manera afectaron a una clasificación artificial de la humanidad y arribaron en suelo latinoamericano influyendo en las orientaciones nacionales sobre la inmigración.

Los planteamientos de Charles Darwin expuestas en On the Origin of Species by Means of Natural Selection or the Preservation of Favoured Races on the Struggle for Life en 1859, y en Descent of Man and Selection in Relation to Sex en 1871, expusieron un cambio copernicano en el campo de las ciencias naturales, clausurando las apelaciones a lo sobrenatural en la evolución humana. Empero, como ha sostenido Jean Marc Bernardini, en el trabajo científico de Darwin podemos distinguir, "entre le discours expérimentalement sanctionné par la science et le discours idéologique véhiculé par le chercheur lui-même" (Bernardini, 2013, par. 5). El tópico entre el crecimiento demográfico y la producción de alimentos, sostenido en 1793 por R. T. Malthus, fue decisivo en la idea darwinista de la selección natural. La coincidencia o bien la complementación de las ideas de Herbert Spencer (la "equilibración directa") con las de Darwin (la "teoría de la selección natural"), aunaron un plano ideológico entre las ciencias naturales y las sociales (Caponi, 2014; Holmes, 1994), donde fueron consolidándose la sociología por Spencer y la antropología por Edward B. Tylor, y de modo recíproco estuvieron al tanto estos autores de los avances del otro (Rodríguez, 2009). Estas ideas darwinistas, como advirtió Hofstadter (1994), impactaron en las maneras de pensar y creer en una sociedad que era moldeada por el espíritu burgués-industrial y con ansias imperialistas, como era la Inglaterra victoriana. El campo del denominado darwinismo social comenzó a irradiarse, con base en los ejes de la "selección natural" y "la supervivencia del más apto", donde lo verificado por la ciencia en la naturaleza fue trasladado al plano de la sociedad, teniendo en Spencer un baluarte fundamental (Buganza, 2010).

La idea de la superioridad de las razas nórdicas condujo a estimar inferiores a las razas amarilla y negra. El propio Darwin, al destinar un capítulo de su libro The Descendent of Man a la extinción de las razas ("On the Extinction of the Races of Man), había planteado que era un hecho histórico que muchas razas y "sub-razas humanas" habían desaparecido de modo parcial o completa, lo cual realzaba el orgullo de la raza caucásica e hizo que el imaginario social racial fuese alimentado por la interpretación que aportaba la biología evolutiva humana (Sánchez Artea- 
ga, 2007a, 2007b). En el despliegue de las razas, la "derrota" de la degeneración evolutiva de las razas no caucásicas, del poligenismo o del hibridismo de las razas humanas (según Paul Broca, o mestizaje), fue el triunfo del hombre blanco (Sánchez Arteaga, 2008). El racismo fue aplicado hacia el interior de los propios países. El primo de Darwin, Francis Galton estableció en 1865 la eugenesia, con su obra Hereditary Genius: An Inquiry into Its Laws and Consequences, una vieja idea en la antigua Grecia que excluía de modo letal a los humanos con deformidades físicas. En Francia, sus seguidores fundaron la "Antroposociología" y en 1912 la Sociedad Francesa de Eugenesia.

Concluyamos que el darwinismo social constituyó una ideología que abarcó a distintos sectores, como refiere Bernardini (2013):

Synonyme d'une vision libérale et cynique de l'humanité ou d'une politique conservatrice et réactionnaire. La «lutte pour l'existence» avantageuse aux "plus aptes», interprétés comme, les meilleurs ou les plus forts, est donc censée légitimer un ordre élitiste, conservateur et socialement hiérarchisé. (par.1) ${ }^{1}$

Los proyectos biopolíticos no solamente se aplicaron en Europa (Sánchez Arteaga, 2008), sino que alcanzaron al continente latinoamericano (Pinho, 2017). El darwinismo en su incidencia racial en Brasil fue conducido por Raimundo Nina Rodrigues, considerado el padre de la antropología médica brasileña y el primer teórico racial importante en la comunidad científica de su país (Glick, Ruiz y PuigSamper, 1999; Sánchez Arteaga, 2017). El darwinismo social se propagó en Bolivia, Argentina y en México (Juárez-Barrera y Bueno-Hernández, 2017; Puig-Samper, Ruiz y Galera, 2002; Urías Horcasitas, 1996; Vallejo y Miranda, 2005).

La biopolítica se aplicó en varios ciclos de acciones sobre poblaciones indígenas y afrodescendientes en territorios de América. Más tarde, se vio afectada la inmigración asiática, primero los chinos y posteriormente los japoneses, después de 1930. También hubo discriminaciones contra los árabes.

La influencia práctica de estas ideas condujo a reacciones populares antiextranjeros.

La sinofobia se verificó por diversos motivos. En México por vincularse a los comerciantes chinos con el porfiriato y, por ende, perseguidos y masacrados por los revolucionarios; en Perú, por rebelarse los culíes en las haciendas y apoyar al ejército chileno en la Guerra del Pacífico (Hu-Dehart, 1980, 1989; Look Tai \& Chee Beng, 2010; Narváez, 2010).

1 Como nos basamos en la versión en línea del libro, citamos por el parágrafo donde se encuentra la cita en vez de la página. 
En el caso de Chile, las ideas científicas y pseudocientíficas de los autores europeos que hemos mentado, produjeron corrientes de opinión que exacerbaron el nacionalismo en momentos en que todavía no se finiquitaban los tratados internacionales fronterizos, en 1889 con Argentina con relación a la Puna de Atacama, en 1904 con la República de Bolivia y en 1929 con Perú, donde las expresiones se canalizaron en un número de escritores nacionalistas que cuestionaron la decadencia de la nación. En la pluma destacó Nicolás Palacios con su libro Raza Chilena (Alvarado-Borgoño, 2004; González Pizarro, 2009) y, en las calles, las manifestaciones populares y mesocráticas de las acciones de las Ligas Patrióticas, en las provincias de Tarapacá y Antofagasta, en 1910 y con rebrotes en 1918 y 1925, con persecuciones contra peruanos y bolivianos (González, Maldonado y McGee Deutsh, 1993).

El darwinismo en Chile enfrentó al clero y al conservadurismo con la intelectualidad liberal, que tampoco exhibió una aceptación completa del evolucionismo, pero divulgó su ideario (Medel y Veloso, 2009; Tamayo Hurtado, 2009;). La eugenesia ganó adeptos en el país, puesto que la inmigración no había acrecentado la población nacional de manera estimable; se procuró que la inmigración "ayudara a mejorar la raza nacional", como lo sostuvo Félix del Campo, en 1911. El rechazo al aporte de los pueblos indígenas y a razas no europeas, fue para no ahondar en males existentes y encontrarse con "una raza debilitada en sus facultades mentales, por el alcoholismo y otras enfermedades", planteó en 1929 Alberto Mackenna Subercaseaux. El control de la inmigración llevó a plantear que hubiese médicos en los puertos para rechazar a los inmigrantes que padecieran enfermedades contagiosas o tuvieran grandes defectos físicos. En la Cámara de Diputados, en 1905, se declamó con recelo la inmigración japonesa, por representar un peligro amarillo y los negros podían debilitar la raza. La xenofobia (el odio a los extranjeros), se encauzó hacia los asiáticos, y con Nicolás Palacios contra los "latinos", especialmente hacia los italianos (Ortíz Valenzuela, 2006). Se ha estudiado que en la década de 1920 los médicos tuvieron un protagonismo en el tratamiento del problema racial chileno, barajándose el aborto para impedir el nacimiento de "seres degenerados" y en la década de 1920 se planteó el Decreto Ley № 355 denominado "En Defensa de la raza" para atacar, con medidas represivas, males como las enfermedades venéreas, tuberculosis y alcoholismo. La influencia germana hizo que en Chile (en la década de 1930) se barajara la esterilización como opción contra estas enfermedades. Hubo una serie de proyectos de ley en tal sentido y un buen número de tesis de grado de Licenciatura en la Facultad de Leyes y Ciencias Políticas en la Universidad de Chile, que abogaron por tales planteamientos. La relación entre eugenesia y Estado constituyó una relación compleja (Letelier Carvajal, 2009).

Las ideas racistas confundidas con la eugenesia tuvieron una gravitación en la formación de la higiene sexual nacional en la década de 1920, divulgadas por 
Waldemar Coutts (Sánchez Delgado, 2018a), Otto Aichel y Erwin Baur (Sánchez Delgado, 2018b). El caso de Aischel fue paradigmático. Nacido en Chile, se destacó en Alemania como hombre de ciencia nazi y formó parte de los Tribunales de Salud Hereditaria del régimen de Hitler. Vinculado también a la colonia germana, estuvo la Botica Daube y Cía, que publicitó gratuitamente el conocido Almanaque 18, con tiraje de 150.000 ejemplares, donde los tónicos farmacéuticos alimentaron "el imaginario sociodarwinista del cuerpo deportivizado, vitalizado y poderoso" (Sánchez, 2009, p. 10).

Este ambiente y las ideas que la sustentaba hizo que los ciudadanos chinos, japoneses (en menor medida) y los provenientes del Medio Oriente sufrieran el racismo, la xenofobia y la discriminación por parte de los sectores populares y mesocráticos nacionales y también, por los sectores políticos de distinto espectro ideológico.

El racismo se manifestó en la vida cotidiana de las ciudades chilenas, donde se radicaron los inmigrantes procedentes del Asia [principalmente en ciudades del norte chileno (Calle Recabarren, 2014; Díaz Aguad, Díaz Araya y Sánchez Espinoza, 2014; González, Lufin \& Llanos 2019b) y del Medio Oriente, en urbes del centro del país. A los procedentes desde Palestina, Siria y el Líbano se les llamó despectivamente "turcos" sin discriminación de su riqueza, encontrando hostilidad en la calle, en sus tiendas o en la prensa (Olguín y Peña, 1990; Rebolledo Hernández, 1994; Samamé, 2003).

Los sectores mayoritarios de la sociedad nortina tuvieron una mirada dual sobre la presencia china. Se les consideraba trabajadores y pacíficos, pero la costumbre culinaria del uso de condimentos y las muestras de adicción a los opiáceos (González, Lufin \& Llanos, 2019a; Fernández Labbé, 2011, 2013), fundamentaron la percepción de su escasa higiene y la degeneración en las drogas. Aquello dio pábulo al racismo ventilado en los medios de prensa vinculados a Agustín Edwards y en la novelística de la generación literaria de 1938 ideológicamente cercana al marxismo-leninismo (Guerrero, 1997).

\section{La política de Estado sobre la inmigración. Entre la selección racial y el recelo}

La Constitución Política de 1833 no señalaba ningún obstáculo al extranjero y aseguraba a este las mismas garantías que al nacional, igualdad ante la ley, la absoluta libertad de movimiento en el territorio, la inviolabilidad de su propiedad, el acceso a la nacionalidad, "que profesando alguna ciencia, arte o industria, o poseyendo alguna propiedad raíz, o capital en giro", se le exigiría seis años de permanencia si era casado y tuviese familia en Chile y "tres años sin son casados con chilena", rezaba el artículo 6, inciso 3 (Valencia, 1968, p. 174). 
Una mirada sucinta a las directrices que tuvo el Estado de Chile en el siglo XIX permite comprender de qué manera se privilegió el elemento europeo en desmedro de otros contingentes demográficos, atendidas las circunstancias por la que pasaba el Estado nación en formación. Se apostaba por la inmigración extranjera para resolver innumerables cuestiones, desde la propiedad nacional, la incorporación del territorio de Arauco y las fronterizas, que "están llamadas a ser sanjadas (sic) más por el hecho de la población, que por las prescripciones escritas de los pactos internacionales" (Durán Migliardi y Thayer, 2017, p. 432).

La inclinación por una política estatal a favor de la inmigración alemana, abrió la trayectoria de una política "selectiva”. El Estado desde 1883 hasta principios del siglo XX, buscó procurar atraer suizos, franceses, alemanes e italianos del norte de su península, mediante la Agencia de Colonización. En tiempos de la administración de José Manuel Balmaceda (1886-1891) se prohibió la entrada de "individuos que no tengan o no puedan ejercer profesión u oficio que los habilite para ganarse la vida y que puedan constituir una carga para el Estado" (Bravo Acevedo y Norambuena Carrasco, 2018, p. 50).

El prejuicio y la discriminación hacia los chinos fue alimentado por los informes de diversos cónsules, v.gr. el de Francisco Segundo Casanueva, ex cónsul chileno en San Francisco, EE.UU. (Jara Fernández, 2002).

El peligro de perder las fuentes de trabajo en sectores populares a manos de los chinos, hizo que el político y líder del Partido Demócrata Malaquías Concha, llegase a proponer un proyecto de ley en 1906: “Artículo Único: Queda prohibida la inmigración en el país de individuos de raza amarilla o mongólica y de raza negra o etiópica" (Díaz Aguad, 2006, p. 63).

La política estatal sobre inmigración abordó cuatro niveles, a nuestro entender, uno, la normativa oficial sobre acciones a llevar a cabo; dos, los convenios a nivel policial para controlar el flujo migratorio; tres, las acciones de las autoridades provinciales y municipales y cuatro, las instrucciones confidenciales emanadas desde el Ministerio de Relaciones Exteriores a las distintas representaciones diplomáticas y consulares.

El 24 de junio de 1905 se estableció el Reglamento de Inmigración Libre que acogió las ideas del darwinismo social en gran medida, pues estimaba que toda persona, "agricultor, minero o capaz de ejercer un oficio, comercio o industria, que siendo menor de cincuenta años; acreditando su moralidad y aptitudes" (Norambuena, Navarrete y Matamoros, 2018, p. 225). Nuevamente, en septiembre de 1907 hubo otro Reglamento de Inmigración Libre para fiscalizar la traída de europeos. Aparte de la documentación se asignó lugares de hospedaje en Talcahuano, Valparaíso y Antofagasta. Así llegaron boers, holandeses y canarios al sur de Chile 
Puntualicemos que en 1907 se creó la Inspección General de Colonización e Inmigración que reemplazó a la Agencia General de Inmigración. La búsqueda de inmigrantes europeos no disminuyó, pero, simultáneamente se procuró fiscalizar a los que se sospechaba estaban imbuidos de ideas contra el orden establecido.

Esta norma de 26 de septiembre de 1907 fue complementada por un par de convenios suscritos en el marco de la cooperación policial. Incluso uno anterior, de 1906, "Convenio celebrado entre las Policías de La Plata i Buenos Aires (Argentina), de Río de Janeiro (Brasil), de Santiago de Chile, de Montevideo (República Oriental del Uruguay), n.o 180, Santiago 18 de enero de 1906" (Anuario del Ministerio del Interior correspondiente al año 1906, 1909, p. 239). Posteriormente, hubo una ampliación mediante el Convenio entre las Policías de Argentina, Brasil, Chile y Uruguay de 20 de octubre de 1910 (González, Lufin \& Llanos, 2019b). Esto significó controlar la llegada de inmigrantes vinculados al anarquismo, principalmente italianos, y también permitió un catastro completo de todo extranjero en el norte, a través de los prontuarios extranjeros. Esto llevó a dictar la denominada Ley 3.446 de Residencia en 1918 para que ningún inmigrante pudiese entrar sin la visa, no tener prontuario penal, no ser de ideas subversivas ni revoltoso, contar con un oficio u profesión, tuviese buena salud (Bravo Acevedo y Norambuena Carrasco, 2018, p. 65). Se vislumbraba, al decir de los autores citados, una mirada policial y de seguridad nacional al fenómeno migratorio. Pero, apostillaríamos, que esta mirada comenzaba en 1906 donde las circunstancias de las huelgas de obreros, principalmente la de la carne de 1905 en Santiago, representó para la clase dirigente el grave peligro de la convulsión y la necesidad de controlar a los extranjeros. Las huelgas y masacres de 1906 en Antofagasta y 1907 en Iquique, refrendaron tal percepción y extremar el control en las zonas salitreras, donde estaba el eje de la economía nacional.

Tales fueron los delineamientos que se van a heredar en el plano de la legislación nacional.

Los instructivos emanados desde el Ministerio de Relaciones Exteriores hacia las representaciones en Asia y Medio Oriente dieron cuenta de una visión migratoria que, encuadrada en los lineamientos señalados, abona el prejuicio y la discriminación, mezclando juicios desde Santiago y lo apreciado desde las destinaciones diplomáticas y consulares. Es un cúmulo de notas que van conformando una acción, una práctica que se correlaciona con lo estimado desde Santiago de Chile.

Las directrices emanadas desde Santiago, en materias de seguridad, fueron observadas en relación con el ingreso de inmigrantes, su fiscalización y expulsión (FIA, 1939, Oficio confidencial Intendencia de Antofagasta, 14 de enero) y, en asuntos sanitarios concernientes al tráfico de opio en la colonia china, por ejemplo, la municipalidad de Antofagasta hizo un seguimiento en la década de 1930 (LSM, vol. 34). 
En cuanto al cuarto nivel, el de las comunicaciones consulares y diplomáticas, espigaremos las más elocuentes en la orientación inmigratoria.

Japón mostró interés por su migración hacia Chile en 1913, interesándose por las franquicias que tendría. A juicio del representante chileno en Tokyo, su conocimiento de las costumbres niponas, hacían "desaparecer en gran parte los temores y objeciones que se hacen generalmente", pero mostraba su cautela ante el asunto (AHMRE, 1913, vol. 446: Oficio Tokyo, diciembre 16 al ministro de RR.EE.). Importante en este sentido fue el análisis que realizó el ministro chileno en Japón sobre los prejuicios vertidos sobre su población en los países anglosajones. En 1908 el gobierno nipón se comprometió a reducir el tráfico de migrantes en sus compañías navieras, aun cuando la resistencia de los sindicatos y agricultores norteamericanos contra los japoneses no decayó: los trabajadores asiáticos trabajaban por menor salarios, no hacían huelgas y la amenaza de la capacidad industrial japonesa, eran las razones de esta xenofobia. El tema central fue que la migración japonesa era auspiciada por el gobierno de Tokyo y formaba parte de una estrategia de procurar una expansión de sus áreas de influencia. Concluía que el verdadero peligro era el económico. Austero, trabajador, que manda remesas de sus ganancias a su país, el japonés se transformó en un peligro/desafío. A su juicio:

En Chile él importaría un factor más de desnacionalización, un factor eficaz de depresión de nuestra economía nacional...La llegada a Chile de esta clase de inmigrantes importa además, una amenaza para los gremios de asalariados nacionales, para los pequeños comerciantes, para todos aquellos que viven dentro de la comunidad ejerciendo industrias intermediarias que, aunque satisfacen las necesidades de terceros, no importan, por si (sic) mismo, el aumento, en un solo centavo, de la producción nacional. (AHMRE, 1913, vol. 463: Informe de Tokio, 20 de enero al ministro de Relaciones Exteriores)

El peligro de la presencia japonesa en Tarapacá estribaba que para el gobierno japonés ningún inmigrante debía retornar a su país y por el contrario se le obligaba a quedarse a perpetuidad en el país de destino. Esto debía estipularse con claridad en el convenio entre ambos países si hubiese que traer mano de obra japonesa.

La molestia con la inmigración china se acrecentó por la acción de la empresa naviera japonesa Toyo Kisan Kaisha en Hong-Kong, en connivencia con su representante en Chile la Casa Grace \& Co. Esto en 1915. El gobierno chileno clausuró su consulado en la ciudad señalada y restringió la inmigración china. Detrás del tráfico de inmigrantes chinos estaba el gran negocio de la especulación de la trata de personas, que requería de la visa consular chilena para viajar, pero el negocio prosiguió (AHMRE, 1915, vol. 514: Oficio Tokyo, 8 de abril al ministro de RR.EE.). Las restricciones a la inmigración china se incrementaron con otras vallas, a fines de 1915, ordenadas desde Santiago: 
"Cobrar diez libras esterlinas por cada pasaporte, previo un estricto examen médico del interesado. Cada emigrante debería, además, presentar un depósito o letra de cambio contra Chile por quince libras esterlinas, para atender sus primeros gastos" (AHMRE, 1915, vol. 514: Oficio Tokyo, 11 de octubre). Se fijó un tope de 15 inmigrantes chinos por viaje de la Toyo Kisan Kaisha. La falsificación de pasaportes refrendó la importancia del negocio del tráfico (AHMRE, 1915, vol. 547: Oficio confidencial, Tokyo, 14 de noviembre). Al parecer determinados cónsules chilenos en Japón desatendieron la orden y concedieron autorización para viajar a 400 chinos por vapor (AHMRE, 1920, vol. 828: Oficio confidencial, Tokio, 27 de mayo; Díaz Aguad, 2006, pp. 69-70).

Los delineamientos respecto a los ciudadanos japoneses y chinos se mantuvieron hasta fines de la década de 1920.

En cuanto a los árabes, el tema fue que Gran Bretaña, asumiendo el Protectorado de Egipto, planteó que los súbditos locales debían gozar de los mismos privilegios (AHMRE, 1920, vol. 1082ª: Oficio del Cónsul General, El Cairo, 8 de marzo).

Bajo la Constitución de 1925 se prosiguió este estatuto de garantías e incluso se amplió a los derechos sociales, sin distinción entre extranjeros y nacionales, "proporcionar a cada habitante un mínimo de bienestar, adecuado a la satisfacción de sus necesidades personales y a las de su familia. La ley regulará esta organización" (Valencia, 1968, p. 217).

Empero, la política oficial de Chile en materias inmigratorias quedó de manifiesta en la Circular n.․12, de 16 de diciembre de 1927, que recogió y sintetizó la influencia del darwinismo social en las esferas políticas:

Este Gobierno, como se habrá US. Enterado por numerosas declaraciones y publicaciones de prensa, tiene el propósito decidido de conservar, mejorándola en lo posible, la composición de nuestra raza que dio pruebas de vigor y de pujanza...Un somero estudio del cruzamiento de diversas razas nos ha probado que los productos de las asiáticas y africanas son a menudo inferiores bajo nuestro clima a cada uno de los componentes, individualmente considerados. Además, hay nacionalidades que, aparte de sus defectos como troncos de familia, los tiene como simples habitantes del país. Así, hemos visto que los eslavos que llegan a Chile, judíos en su mayor parte, y de escasa cultura, son revoltosos y sembradores de doctrinas malsanas que han sido causa de desórdenes universitarios y de no pocos disturbios populares... Nunca muestran apego a país alguno, ni al de origen ...Los sirios y palestinos, además de ser inadaptables a nuestras costumbres, e inadecuados para formar familia entre nosotros, pertenecen a pueblos del más bajo estándar de vida, que les permite competir en forma desleal con las razas superiores...Su falta de honradez en los negocios se ha hecho proverbial... Si las nacionalidades mencionadas llegasen a las 
profesiones liberales y particularmente a las relacionadas con la salud pública, creo que las consecuencias serían fatales para el país. Nada diré a US. Acerca de las nacionalidades china, indostánicas, africanas y otras, ya que el sentimiento público de los países medianamente avanzados las rechaza con elocuente unanimidad...En cambio el país recibirá con agrado y estudia la manera de impulsar la inmigración de todas aquellas razas de origen europeo que fueron artífices de la nuestra y que formaron la patria vieja... y los ciudadanos que hicieron grande, próspera y respetable a la República...dar cumplimiento estricto a nuestras leyes de Residencia y Sanitarias...para evitarnos las continuas solicitaciones de representantes de potencias que tienen protectorados y mandatos sobre razas inferiores y para evitarnos el sentimiento de no acojerlas (sic)...individuos que, considerados indeseables, pretendan emigrar a la República. (Circular n.ํㅜ 12, 16 de diciembre de 1927)

La Circular fue enviada a todas las representaciones chilenas en el mundo y firmada por el Ministro de Relaciones Exteriores, Conrado Ríos Gallardo (AHMRE, 1927, vol. 1110B: Oficio confidencial n. $\stackrel{0}{12}$, Santiago, 16 de diciembre, sobre visación de pasaportes a indeseables. Destacados son nuestros)

\section{La adecuación de la política migratoria al canon de los derechos humanos y el impacto de la inmigración masiva latinoamericana en la segunda década del siglo XXI}

La llegada de flujos inmigratorios latinoamericanos desde fines de la década del 2000 significó una revisión de la normativa migratoria chilena. Y esto se transformó en urgencia cuando se constató el salto cuantitativo en el 2012 y una explosión inmigratoria en el bienio 2017-2018. Precisamente, el Instructivo Presidencial de 6 de noviembre de 2015, reconocía a Chile, como "país de migración... un aporte fundamental para la definición de cultura" (Instructivo Presidencial n. ${ }^{\circ}$, 2015).

Los cómputos de extranjeros evidenciaban la realidad reconocida en el año 2015, pues se pasó de un 0,8 \% en 1992 a un 2,3 \% en el 2014 (Departamento de Extranjería, 2016, p. 21).

Las cifras demográficas desde el año 2005 iban indicando una tendencia dual, por un lado, una mayor concentración geográfica de la inmigración latinoamericana tradicional (Perú, Bolivia y Argentina) y, por otro, la emergencia fuerte desde otras latitudes de América del Sur (Colombia, Ecuador y Venezuela). La feminización del proceso constataba otra característica, dado que, en el año 2014, el 52,6 \% de los inmigrantes fueron mujeres. 
El censo de población del 2017 mostró el incremento explosivo de extranjeros en el país, como lo refiere la Tabla 5 y su porcentaje de extranjeros en el país se alzaba en un 4,4 \% (Instituto Nacional de Estadística [INE], 2018, p. 17). Y también, un cambio radical de la procedencia geográfica y la presencia afrodescendiente de colombianos y haitianos.

Tabla 5: Principales grupos nacionales extranjeros, cantidad y porcentaje en Chile

\begin{tabular}{ll}
\hline Perú & 187.756 personas $25,2 \%$ \\
Colombia & 105.445 personas, $14,1 \%$ \\
Venezuela (República Bolivariana de) & 83.045 personas, $11,1 \%$ \\
Bolivia (Estado Plurinacional de) & 73.796 personas, $9,9 \%$ \\
Argentina & 66.491 personas, $8,9 \%$ \\
Haití & 62.683 personas, $8.4 \%$ \\
\hline
\end{tabular}

Fuente: INE, 2018, p. 24.

La distribución de la población inmigrante volvió a replicar la concentración en las regiones del norte chileno, la antigua provincia de Tarapacá, dividida en dos regiones Arica y Parinacota y Tarapacá, y la región de Antofagasta (con el mismo territorio de la antigua provincia de Antofagasta).

Empero, para el año 2018 el panorama inmigratorio iba a modificarse sensiblemente (Tabla 6), donde la procedencia de los inmigrantes, salvo el caso de peruanos, se alteró con la llegada de venezolanos, haitianos y de los colombianos que quedaban rezagados a un cuarto lugar. Esto incidió en la percepción de la sociedad nacional y regional ante los extranjeros. Al conocido racismo que hemos mentado para el periodo de 1907, contra asiáticos y turcos, ahora se canalizaba contra los afrodescendientes de Colombia, Haití, no faltando rasgos discriminatorios contra otros latinoamericanos.

Tabla 6: Población extranjera en Chile al 31 de diciembre de 2018

\begin{tabular}{ll}
\hline Venezuela & 288.233 personas \\
Perú & 223.923 personas \\
Haití & 179.338 personas \\
Colombia & 146.582 personas \\
Bolivia & 107.346 personas \\
Argentina & 74.713 personas \\
Ecuador & 36.994 personas \\
\hline
\end{tabular}

Fuente, INE, 2019, p. 21. 
Cabe señalar que las ideas emanadas desde darwinismo social impregnaron incluso a los gobiernos del Frente Popular y además se reforzó nuevamente en el segundo gobierno de Ibáñez del Campo (1952-1958), con la dictación del DFL n. 69 del 27 de abril de 1953 que, en lo sustantivo en cuanto a la regulación migratoria, tuvo por finalidad el mejoramiento de la raza (art.12). A nuestro entender, las ideas que hemos observado en el periodo anterior a 1930, en materias raciales, condicionaron las orientaciones del Estado durante la vigencia del régimen democrático hasta 1973.

Durante la dictadura militar de Augusto Pinochet se dio una inflexión a la política migratoria. El giro apuntaba a la influencia de la Doctrina de Seguridad Nacional en los contenidos del Decreto Ley n. $\stackrel{0}{1.094}$, de 19 de julio de 1975. Lo relevante de esta normativa ha sido que se proyectó hasta la irrupción inmigratoria masiva, dejando una amplia discrecionalidad administrativa a la policía de extranjería, exigiendo a los no nacionales ingresar por los lugares habilitados, tener buenas costumbres, no adherir a ideologías atentatorias al orden político, contar con recursos para su manutención y tener personas conocidas en el país.

La nueva realidad migratoria hizo variar la posición del Estado. Dos Instructivos Presidenciales ${ }^{2}$ fueron fundamentales para observar esta inflexión. El Instructivo Presidencial n. ${ }^{\circ}$ 9, de 2 septiembre de 2008, se hizo cargo del arribo de "miles de extranjeros cada año" y esta realidad nueva "debe ser observada bajo el prisma de los derechos ciudadanos", reconociendo a Chile "como país receptor de cuotas significativas de inmigrantes". En consecuencia, se instruyó a los órganos del Estado, para que "consideren en sus programas...los acuerdos y convenios internacionales firmados por Chile en esta materia". Dentro de esta política se incluyó a los movimientos de refugiados, personas desplazadas, etc. Se buscaba la integración del inmigrante, "dentro de la sociedad, respetando su especificidad cultural...con el respeto a la institucionalidad democrática, de la lengua nativa y de ciertos modelos culturales propios del país receptor", haciendo reservas que el Estado no renunciaba a "su rol de orientar el acceso a la residencia, cuando ello sea necesario en beneficio del estado y de las personas que habitan en su territorio" (Instructivo Presidencial n. ${ }^{\circ}$, 2008).

En el Instructivo Presidencial n. ${ }^{\circ}$, de 5 de noviembre de 2015, se acoge las características que se han observado de la inmigración, para fortalecer "una mirada más inclusiva", para promocionar y aplicar los diversos instrumentos internacionales en la materia, que permita el acceso del inmigrante a la salud, trabajo,

2 De acuerdo a la Presidencia de la República, en su sitio “Gobierno Transparente”, estos son documentos emitidos "bajo la firma del Presidente de la República que tienen como objetivo fijar la política de la administración sobre un tema específico, más allá de las normas que rijan el tema de que se trate". Los Instructivos Presidenciales no son correlativos en su numeración. No se consignan en el Diario Oficial.

https://www.guiadigital.gob.cl > articulo > instructivos-presidenciales (Consultado el 22 de octubre de 2019) 
vivienda, educación, cultura y justicia "bajo el principio de la no discriminación". El Instructivo fijaba los ejes de la política migratoria, con base en el enfoque transversal de derechos humanos y de género, la no discriminación, la consideración de grupos vulnerables, la interculturalidad, la regularidad migratoria, etc., para los inmigrantes (Instructivo Presidencial n. ${ }^{\circ}$ 5, 2015).

En consecuencia, dos temas presentes, el racismo y la discriminación, fueron afrontados de manera decidida. En este sentido, también podemos apreciar distintos niveles legales que han permitido, desde el Estado y sus agencias, ir modificando los condicionantes que hemos apuntado. Un primer nivel, ha sido el cuerpo jurídico que penaliza el racismo y la discriminación. La Convención Internacional sobre Eliminación de todas las Formas de Discriminación Racial, de 1979, fue promulgada como ley en el último tiempo del régimen de Augusto Pinochet, el 18 de diciembre de 1989.

Con la denominada Ley Zamudio (Ley n.1을.609, de 12 de julio de 2012), se penalizó toda forma de discriminación. Empero, la mayor dificultad radica en la discriminación práctica, respecto de la intencional, donde la atención no repara en la intención del que discrimina sino en la evaluación del resultado que produce. Un segundo nivel, ha sido el progreso respecto de las principales convenciones internacionales y la adecuación de la legislación nacional en la materia, v.gr. Ley 19.273 de 1993, que regula la salida y entrada a extranjeros en el territorio nacional, la Ley 19.476 de 1996, que en el tópico de asilo y refugio, reconoce el principio de no devolución y despenaliza el ingreso irregular al territorio nacional, Ley 19.581 de 1998, que crea la figura de "habitante de zona fronteriza", facilitando el ingreso y salida de las personas que cumplan las condiciones entre determinados países, Decreto 2.910 de 2000, que permite a los solicitantes de residencia temporaria y sujeta a contrato, obtener autorización para trabajar mientras se tramita su permiso de residencia, Ley 20.430 de 2010, que establece disposiciones sobre protección de refugiados (Díaz Tolosa, 2016; Galdamez Zelada, Lages de Oliveira y López Garrido, 2016; Biblioteca del Congreso Nacional, 2018). Un tercer nivel, lo ha constituido las diversas instrucciones presidenciales (principalmente por la presidenta Bachelet), en materias de salud, educación, respecto a hijos (as) de inmigrantes (González Pizarro y González Tello, 2019). No obstante, el tema del racismo y la xenofobia ha evidenciado un problema en diversos ámbitos, siendo denunciado el denominado racismo estructural por el Instituto Nacional de Derechos Humanos (2018). Aun así, el racismo ha asumido máscaras más sutiles. Lo que hemos señalado como fuentes ideológicas modernas del racismo, ha impregnado otras expresiones del racismo en la práctica cotidiana, en las interacciones subjetivas, en las vinculaciones de las agencias estatales con los inmigrantes (Tijoux, 2016; Tijoux y Córdova, 2015) hasta manifestarse en las segregaciones espaciales de determinados barrios en las principales ciudades chilenas, donde los inmigrantes afrodescendientes, colombianos, haitianos y dominicanos, son 
visibles (Aguirre, 2018; González, Lufin, Echagüe, González, Cortés \& Brizuela, 2019; González Pizarro, 2019a)

La cuestión de la prolongación en la normativa nacional de determinados sesgos selectivos, ha sido asumida de diversas formas. Para algunos (Norambuena et al., 2018), la mayoría de los países tienen modelos inmigratorios selectivos, principalmente en cuanto a su capital social, y la política chilena estaría encuadrada en la teoría de la "Dependencia de la Trayectoria" en cuanto a su institucionalidad; otros como: Stefoni, Lube y Gonzalvez (como se citaron en Tijoux y Córdova, 2015) se plantean la selectividad con relación a la seguridad nacional, protección de derechos humanos y desarrollo de las economías locales, frente a haitianos y venezolanos. La contradicción estriba en la mantención de la normativa de 1975 y los proyectos de nueva ley migratoria de Michelle Bachelet y Sebastián Piñera ajustada al imperio de los derechos humanos.

Aun así, ha habido una disonancia perceptual entre las entidades estatales y la sociedad respecto a la materia migratoria. Determinadas encuestas muestran todavía la persistencia del racismo y la xenofobia en diversos sectores sociales, a pesar que diversas ONG han complementado la labor de mentalización sobre los derechos humanos hacia los nuevos ciudadanos en el territorio nacional y especialmente en el norte chileno, lográndose un cambio en la percepción a favor de los inmigrantes.

\section{Conclusiones}

El tópico de la normativa migratoria en Chile durante el siglo XX estuvo dominado por las ideas en boga en Europa en el tema racial. La aplicación de las ideas de Darwin, sobre la "lucha por la vida" y la "supervivencia del más apto" en el campo de las ciencias sociales, orientados por la obra de Spencer, dieron lugar al denominado darwinismo social. Esto se tradujo en un racismo, que valoró a la raza blanca por sobre la no europea, la necesidad de controlar el buen nacer, la eugenesia, desterrando a los seres con defectos físicos y mentales como inútiles a la sociedad, y apuntando a la plausibilidad de la esterilización para aquellos con enfermedades antisociales, las venéreas, el alcoholismo y los drogadictos.

La importancia de estas ideas arropadas de un pseudo cientificismo, influyeron en sectores dirigentes en cuanto a la toma de decisión en el mundo europeo y latinoamericano. En Chile, la recepción de estas ideas, en momentos que se constataba un frustrado poblamiento del territorio y el surgimiento de una prosa nacionalista que exaltaba el chovinismo, se domesticaron en diversas políticas públicas, especialmente en lo concerniente a materias migratorias. De este modo, la normativa pertinente apuntó hacia una inmigración selectiva, europea, 
con displicencia de elementos asiáticos y africanos. Incluso se proyectó hacia las ideologías consideradas disolventes del orden sociopolítico establecido. Y en el plano interno, el mejoramiento de la raza se correlacionó con diversos proyectos y dispositivos a favor de la eugenesia, la esterilización.

La influencia de estas ideas (en la prensa, en la academia, etc.) contribuyó a la construcción de un imaginario social de "superioridad" racial del chileno, que se complementó con diversas normas e instructivos que refrendaron tal óptica.

La llegada de la inmigración latinoamericana masiva en los últimos años de la década de 2010, visibilizó la contradicción entre la recepción formal de diversos instrumentos internacionales de derechos humanos y migratorios con la permanencia de una política selectiva y restrictiva a la vez, dada la vigencia de la norma de 1975 que faculta la amplia discrecionalidad administrativa sobre expulsión. Pero, también, obligó a combatir los rasgos de racismo y xenofobia subyacentes en la sociedad nacional promulgando leyes e instructivos presidenciales a favor de la inclusividad del inmigrante, una vez superado la situación irregular hacia la visa de residencia permanente, en el ejercicio de una ciudadanía plena.

Aun así, como se ha expuesto, el periodo ideológico del darwinismo social anterior a 1930, se ha transformado, como el mito de Sísifo, en la perpetuación de expresiones y conductas racistas y xenófobas hacia determinados segmentos inmigratorios, que eran estimados "indeseables", los afrodescendientes; de ahí, la importancia de establecer los lineamientos ideológicos y sus ejes, para observar la persistencia de una disonancia perceptual entre la mirada estatal y la sociedad, en distintos ámbitos. Un desafío que muestra la necesidad (y valoración) de la inmigración latinoamericana y la urgencia de desterrar estereotipos sociales sobre esta.

\section{Referencias bibliográficas}

Aguirre, N. (2018). ¿Es Chile racista? Reflexión en torno a las nuevas migraciones latinoamericanas y el caso particular del barrio Yungay (tesis de maestría). Santiago de Chile, Instituto de Estudios Urbanos. Pontificia Universidad Católica de Chile.

Alvarado-Borgoño, M. (2004). La modernidad maldita de Nicolás palacios: Apuntes sobre Raza Chile. Gaceta de Antropología, 20, 1-9.

Anuario del Ministerio del Interior correspondiente al año 1906. (1909). Santiago de Chile: Imprenta Nacional.

Arendt, H. (2004). Los orígenes del totalitarismo. Madrid: Editorial Taurus.

Bernardini, J.M. (2013). Le darwinisme social en France (1859-1918). Fascination et rejet d'une ideologie. C.N.R.S Histoire. Recuperado de https://books.openedition. org.editionscnrs 
Biblioteca del Congreso Nacional. (2018). Migración en Chile: tres perspectivas de análisis. Valparaíso: Departamento de Servicios Legislativos y Documentales.

Bravo Acevedo, G. y Norambuena Carrasco, C. (2018). Procesos migratorios en Chile: una mirada histórica-normativa. Santiago de Chile: Academia Nacional de Estudios Políticos y Estratégicos (ANEPE).

Buganza, J. (2010). Cuestiones filosóficas acerca del darwinismo. Stoa, 1(1), 5-19.

Calle Recabarren, M.A. (2014). Hijos del Dragón: Inmigrantes chinos y su inserción socioeconómica en la Provincia de Tarapacá, 1860-1940. Revista de Ciencias Sociales, (32), 25-62.

Cano, V. y Soffia, M. (2009). Los estudios sobre migración internacional en Chile: apuntes y comentarios para una agenda de investigación actualizada. Papeles de Población, 15(61), 129-167.

Caponi, G. (2014). Herbert Spencer: entre Darwin y Cuvier. Scientiae Studia, 12(1) 45-71.

Chile. Archivo Histórico del Ministerio de Relaciones Exteriores de Chile (AHMRE). (1913). Oficios recibidos de la Legación de Chile en Japón. Vol. 446.

Chile. Archivo Histórico del Ministerio de Relaciones Exteriores de Chile (AHMRE). (1913). Volumen Irarrázaval. Inmigración japonesa en América. Informes. Vol. 463.

Chile. Archivo Histórico del Ministerio de Relaciones Exteriores de Chile (AHMRE). (1915). Oficios recibidos de la Legación de Chile en Japón. Vol. 514.

Chile. Archivo Histórico del Ministerio de Relaciones Exteriores de Chile (AHMRE). (1915). Sección Clave. Telegramas. Cambios con las legaciones en Italia, Japón y Santa Sede. Vol. 547.

Chile. Archivo Histórico del Ministerio de Relaciones Exteriores de Chile (AHMRE). (1920). Legación de Chile a y de Legaciones. Vol. 828.

Chile. Archivo Histórico del Ministerio de Relaciones Exteriores de Chile (AHMRE). (1920). Consulado de Chile en América, Europa, Asia y África. Vol. 1082a .

Chile. Archivo Histórico del Ministerio de Relaciones Exteriores de Chile (AHMRE). (1927). Legación de Chile en Francia. Vol. 1110B.

Chile. Instructivos Presidenciales (s.f.). Definición. Recuperado de https://www.guiadigital.gob.cl>articulo<instructivos-presidenciales

Chile. Instructivo Presidencial n.o 9 (2008, 2 de septiembre). Santiago de Chile, "Imparte Instrucciones sobre la Política Nacional Migratoria”. Recuperado de https:// transparenciaactiva.presidencia.cl/normativa_a8.html

Chile. Instructivo Presidencial n.o 5 (2015, 6 de noviembre). Santiago de Chile, "Lineamientos e Instrucciones para la Política Nacional Migratoria". Recuperado de https://migrantes.mineduc.cl/wp-content/uploads/sites/88/2017/04/6Instructivo-Presidencial-Migracio\%CC\%81n.pdf 
Comisión Central del Censo. (1907). Memoria Presentada al Supremo Gobierno Censo 1907. Recuperado de http://historico.ine.cl/canales/usuarios/cedoc_online/ censos/pdf/censo_1907.pdf

Departamento de Extranjería y Migración del Ministerio del Interior y Seguridad Pública. (2016). Migración en Chile 2005-2014. Santiago de Chile: Sección de Estudios del Departamento de Extranjería y Migración del Ministerio del Interior y Seguridad Pública.

Díaz Aguad, A. (2006). Los consulados chilenos en oriente y su participación en el proceso de inmigración china al norte de Chile (1910-1929). Diálogo Andino, 27, 61-74.

Díaz Aguad, A., Díaz Araya, A. y Sánchez Espinoza, E. (2014). Comercio local y redes sociales de la población china en Arica y Tarapacá, Chile (1900-1930). Interciencia, 39(7), 476-482.

Díaz Tolosa, R. (2016). Ingreso y permanencia de las personas migrantes en Chile: compatibilidad de la normativa chilena con los estándares internacionales. Estudios Constitucionales, 14, (1), 179-220.

Dirección General de Estadística. (1925). Censo de Población de la República de Chile levantado el 15 de diciembre de 1920. Santiago: Imprenta Universo.

Dirección General de Estadística. (1931). Resultados del X Censo de Población efectuado el 27 de noviembre de 1930 (vol. I). Santiago: Imprenta Universo.

Dirección General de Estadística. (1933). Resultados del X Censo de Población efectuado el 27 de noviembre de 1930 (vol. II). Santiago: Imprenta Universo.

Durán Migliardi, C. y Thayer, L.E. (2017). Los migrantes frente a la ley: continuidades y rupturas en la legislación migratoria del Estado chileno (1824-1975). Historia 396, 7(2), 429-461.

Fernández Labbé, M. (2011). Drogas en Chile 1900-1970: Mercado, consumo y representación. Santiago de Chile: Ediciones Universidad Alberto Hurtado.

Fernández Labbé, M. (2013). Boticas y toxicómanos: origen y reglamentación del control de drogas en Chile, 1900-1940. Atenea, 508, 73-89.

Archivo Nacional (Santiago): Fondo Intendencia de Antofagasta (FIA). Correspondencia con el Ministerio de Relaciones Exteriores (1939).

Archivo Municipal de Antofagasta: Libro de Sesiones Municipales (LSM). Vol. 34. Noviembre de 1937-Noviembre de 1939.

Galdamez Zelada, L., Lages de Oliveira, R. y López Garrido, V. (2016). Migración y derechos humanos. Informe temático. Santiago de Chile: Facultad de Derecho, Universidad de Chile. Centro de Derechos Humanos.

Glick, T.F., Ruiz, R. y Puig-Samper, M. Á. (Eds.). (1999). El darwinismo en España e Iberoamérica (Vol. 8). Madrid: Universidad Nacional Autónoma de México, Consejo Superior de Investigaciones Científicas, Ediciones Doce Calles. 
González Pizarro, J. A. (2009). La literatura de ensayo y las imágenes nacionales de Chile y Bolivia a comienzos del siglo XX. Revista Universum, 24(1) 82-109.

González Pizarro, J. A. (2019a). Los campamentos de inmigrantes de Antofagasta (Chile): laboratorio de la resignificación del género y las políticas públicas. Ponencia presentada en el II Congreso Internacional "Políticas Públicas en defensa de la inclusión, la diversidad y el género”, Universidad de Salamanca, España.

González Pizarro, J.A. y González Tello, P. (2019). Migración latinoamericana en situación de marginalidad. Campamentos y educación en Antofagasta, 2012-2018. Revista Estudios Pedagógicos.

González Pizarro, J.A., Lufin Varas, M. \& Llanos, C. (2019a). Notas sobre tres problemáticas de la inmigración china en el norte de Chile. Elementos para una discusión. Inédito

González Pizarro, J.A., Lufin Varas, M. \& Llanos, C. (2019b). Chinese Immigration in Antofagasta at the Beginning of the 20th Century. Its insertion in the Nitrate World. MS.

González Pizarro, J. A., Lufin Varas, M., Echagüe, C., González, P., Cortés, C. A. y Brizuela, A. S. (2019). Una mirada al migrante en Antofagasta. Proyecto IMI-UCN. Antofagasta: Escondida BHP- Ediciones Universitarias de la Universidad Católica del Norte.

González, S., Maldonado, C. y McGee Deutsh, S. (1993). Las Ligas Patriotas. Revista de Ciencias Sociales, 2(2).

Guerrero, B. (1997). Los chinos, su identidad y su lugar en la literatura nortina. Estudios Atacameños, 13, 95-103.

Gurwitsch, A. (2010). Algunas raíces filosóficas del nazismo. Contrastes. Revista Internacional de Filosofía, 10, 363-376.

Hofstadter, R. (1994). Social Darwinism in American Thought. Boston: Beacon Press.

Holmes, B. (1994). Herbert Spencer (1820-1903). Perspectivas: Revista trimestral de educación comparada, (3), 543-565.

Hu-Dehart, E. (1980). Inmigrants to a developing society: The Chinesse in Northern Mexico: 1872-1932. The Journal of Arizona History, 21(3), 275-312.

Hu-Dehart, E. (1989). Coolies, Shopkeepers, Pioneers: The Chinese of Mexico and Peru (1849-1930). Amerasia Journal, 15(2), -116.

Instituto Nacional de Derechos Humanos (Chile). (2018). Manifestaciones de discriminación racial en Chile: un estudio de percepción. Recuperado de https://www. indh.cl/bb/wp-content/uploads/2018/01/Cap1_Manifestaciones.pdf

Instituto Nacional de Estadística (INE). (2018). Características de la Inmigración internacional en Chile. Censo 2017. Santiago: INE. Recuperado de https://www. censo2017.cl/descargas/inmigracion/181123-documento-migracion.pdf

Instituto Nacional de Estadística (INE). (2019). Estimación de personas extranjeras residentes en Chile al 31 de diciembre de 2018. Santiago: INE. Recuperado de https:// www.ine.cl/docs/default-source/default-document-library/estimaci\%C3\%B3n- 
de-personas-extranjeras-residentes-en-chile-al-31-de-diciembre-de-2018. pdf?sfvrsn $=69145 \mathrm{bd} 200$

Jara Fernández, M. (2002). Chinos en Chile: Política consular y debate parlamentario a comienzos del siglo XX. Valparaíso: Servicio de Imprenta de la Universidad de Playa Ancha.

Juárez-Barrera, F. y Bueno-Hernández, A. (2017). La influencia del darwinismo sobre los conceptos raciales en México. Asclepio. Revista de Historia de la medicina y de la Ciencia, 69(1). 174-ss.

La Placa, Ch. (2017). Natural Selection to Neo-Darwinism: Societal Confrontations of Evolutionary Biology. Emergence. Recuperado de https://emergencejournal. english.ucsb.edu/index.php/2017/11/25/801/

Look Tai, W. \& Chee Beng, T. (eds.). (2010). The Chinese in Latin America and the Caribbean. Boston: Editorial Brill.

Letelier Carvajal, J. (2009). “Gobernar es poblar...seleccionadamente”. Ideas eugenésicas en Chile 1925-1941: una mirada científica y política hacia los intentos por mejorar "la raza chilena" (tesis de grado). Universidad Alberto Hurtado, Santiago de Chile, Chile.

Medel, R. y Veloso, A. (2009). Establecimiento y propagación del darwinismo en Chile: Recepción y elaboración de las ideas. Gayana, 73, 7-18.

Narváez, B. N. (2010). Chinese Coolies in Cuba and Perú: Race, Labor, and Immigration, 1839-1886. (doctoral thesis). The University of Texas, Austin, U.S.

Norambuena, C., Navarrete, B.y Matamoros, R. (2018). Entre continuidades y rupturas, mejor la continuidad. Política migratoria chilena desde comienzo del siglo XX. Revista Austral de Ciencias Sociales, (34), 217-237.

Olguín, M. y Peña, P. (1990). La inmigración árabe en Chile. Santiago: Ediciones Instituto Chileno Árabe de Cultura.

Ortíz Valenzuela, M.G. (2006). Eugenesia en Chile. El camino hacia la manipulación racial de un pueblo mestizo, 1900-1940 (Memoria de licenciatura). Universidad Finis Terrae, Santiago de Chile, Chile.

Pinho, O. (2017). Racismo y raza. Enciclopedia Latinoamericana. Sao Paulo.Htm.

Puig-Samper, M. A., Ruiz, R. y Galera, A. (2002). Evolucionismo y Cultura. Darwinismo en Europa e Iberoamérica. Madrid: Junta de Extremadura, Universidad Nacional Autónoma de México, Ediciones Doce Calles.

Rebolledo Hernández, A. (1994). La “Turco Fobia”. Discriminación antiárabe en Chile, 1900-1950. Historia, 28, 249-272.

Rodríguez, G. (2009). El legado radical de Charles R. Darwin a las ciencias sociales. Antípoda, 9, 267-282.

Samamé, M. O. (2003) Transculturación, identidad y alteridad en novela de la inmigración árabe hacia Chile. Revista Signos, 36 (53), 51-73. 
Sánchez, M. (2009). Tónicos y darwinismo social: imaginario de la salud en el Almanaque 19, Chile, 1920-1930. Eâ, 1(2). Recuperado de https://issu.com/eajournal/ docs/tónicos-y-darwinismo-social-almanaque-18

Sánchez Arteaga, J. M. (2007a). La razón salvaje. La lógica del dominio: tecnociencia, racismo y racionalidad. Madrid: Ed. Lengua de Trapo.

Sánchez Arteaga, J. M. (2007b). La racionalidad delirante: el racismo científico en la segunda mitad del siglo XIX. Revista de la Asociación Española Neuropsiquiatría, 27(2), 111-126.

Sánchez Arteaga, J. M. (2008). La biología humana como ideología: el racismo biológico y las estructuras simbólicas de dominación racial a fines del siglo XIX. THEORIA, Revista de Teoría, Historia y Fundamentos de la Ciencia, 23(1), 107-124.

Sánchez Arteaga, J. (2017). Biological Discourses on Human Races and Scientific Racism in Brazil (1832-1911). Journal of the History of Biology, 50, 267-314.

Sánchez Delgado, M. (2018a). Sexo, eugenesia y política. Waldemar Coutss (Chile, 1895-1959). Revista Historia, 24(1), 109-130.

Sánchez Delgado, M. (2018b). La higiene racial explicada a los chilenos: las conferencias de Otto Aichel (1927) y Erwin Baur (1930) en Santiago de Chile. Revista de Historia Social y de las Mentalidades, 22(2), 225-246.

Tamayo Hurtado, M. (2009). Charles Darwin y el darwinismo en Chile. Theoria, 18(1), 19-33.

Tijoux, M. E. (Ed.). (2016). Racismo en Chile: la piel como marca de la inmigración. Santiago de Chile: Editorial Universitaria.

Tijoux, M. E. y Córdova R. M. (Eds.). (2015). Número dedicado al racismo en Chile. Revista Polis, 14(42).

Weikart, R. (2013). The Role of Darwinism in Nazi Racial Thought. German Studies Review, 36 (3), 537-556.

Valencia, L. (1968). Anales de la República. Tomos I y II actualizados. Santiago de Chile: Editorial Andrés Bello.

Vallejo, G. y Miranda, M. (2005). Darwinismo social y Eugenesia en el mundo. Buenos Aires: Editorial Siglo XXI.

Urías Horcasitas, B. (1996). El determinismo biológico en México: del darwinismo social a la sociología criminal. Revista Mexicana de Sociología, 58(4), 99-126. 